\title{
Prevalence, Risk Factors and Outcome of Preterm Births at University of Maiduguri Teaching Hospital (UMTH), Maiduguri, Nigeria: A 2-year Case-Control Study
}

\author{
Obetta Hillary Ikechukwu ${ }^{1}$, Babagana Bako ${ }^{1}$, Nweze Sylvester Onuegbunam², \\ Ezenwaeze Malachy Nwaeze ${ }^{2}$
}

${ }^{1}$ Department of Obstetrics and Gynaecology, University of Maiduguri Teaching Hospital, Maiduguri, Nigeria ${ }^{2}$ Department of Obstetrics and Gynaecology, ESUT College of Medicine/Teaching Hospital, Parklane, GRA, Enugu Nigeria

Corresponding Author: Ezenwaeze Malachy Nwaeze

\section{ABSTRACT}

Background: Preterm birth (PTB) is an important cause of perinatal morbidity and mortality in developing societies like Nigeria. It poses huge long-term medical and financial burdens for the affected children, their families, the health care system and society at large.

Objective: The objective of this study was to determine the prevalence, risk factors and birth outcome of PTB at UMTH, Nigeria.

Methodology: A two-year case-control study of cases of preterm births at the UMTH, from $1^{\text {st }}$ January, 2016 to $31^{\text {st }}$ December, 2017 was undertaken. For each PTB, the next term delivery was taken as control. Information on socio-demographic characteristics, risk factors, gestational ages at presentation and delivery, and birth outcome were obtained from the women's case files with proforma and compared with that of the control. Statistical analysis was done using Statistical Package for the Social Sciences (SPSS) software Version 23. The statistical significance was set at $\mathrm{P}<0.05$.

Results: During the period under review, there were 6,171 deliveries and preterm births constituted 291 births giving a prevalence rate of $4.7 \%$ or 47 per 1000 deliveries. The mean ages for the cases and controls were similar $26.4 \pm 6.1$ vs $26.5 \pm 5.3$ with $(\mathrm{F}=0.15, \mathrm{P}=0.7)$ while the mean parity were $3.0 \pm 2.6$ and $3.2 \pm 2.5$ with $(\mathrm{F}=4.6, \quad \mathrm{P}=0.03)$. Nulliparity was commoner among the cases 61(24.6\%) compared to the controls $34(13 . .7 \%)$ with $\mathrm{X}^{2}=$
\end{abstract}

9.69, $\mathrm{P}=0.001$. Similarly, $96(38.7 \%)$ of the cases were unbooked compared to $44(17.7 \%)$ among the conrols $\mathrm{X}^{2}=26.9, \mathrm{P}=0.000$. About $20 \%$ of the cases had no formal education compared to $13 \%$ of the control. Preterm birth was associated with unbooking status $(\mathrm{OR}=1.82$, CI: 1.40$2.36)$, nulliparity ( $\mathrm{OR}=2.05$, CI: 1.29-3.26), previous preterm delivery $(\mathrm{OR}=95.2, \mathrm{CI}$ : 13.10-691.99) and pregnancy induced hypertension $(\mathrm{OR}=25.45, \mathrm{CI}:$ 9.13-70.92). Antepartum haemorrhage $(\mathrm{OR}=13.89$, CI: 4.92-39.25), twin gestation $(\mathrm{OR}=18.18$, CI: 2.40-137.68), Polyhydramnios $(\mathrm{OR}=2.02$, CI: 1.85-2.22) and PROM (OR $=5.39$, CI: 2.8710.15) were other risk factors independently associated with PTB. The perinatal mortality in PTB was 43(16.2\%).

Conclusion: The prevalence rate of PTB at the UMTH is $4.7 \%$ and is associated with previous PTB, unbooked status, twin gestation, polyhydramnios, APH and PIH. Efforts should be intensified on educating women of reproductive age group on the benefits of antenatal booking in pregnancy and quality antenatal care as this would provide ample opportunity for early detection and proper management of women at risk.

Keywords: Preterm birth, Risk factors, Neonatal outcome, Maiduguri.

\section{INTRODUCTION}

The World Health Organization (WHO) has defined preterm birth as any 
birth before 37 completed weeks of gestation or fewer than 259 days since the first day of a woman's last menstrual period ${ }^{[1]}$. Preterm birth (PTB) is a major global problem because it is associated with significant morbidity and mortality in the perinatal, neonatal and childhood periods ${ }^{[2-}$ 4]. Even beyond these periods, survivors have worse neural development, poor school performance, increased risk of cerebral palsy and metabolic diseases in adulthood ${ }^{[5-}$ ${ }^{7]}$. Hence, PTB is a major cause of long-term loss of human potential among survivors ${ }^{[1-}$ 4].

In view of the global concern about the burden of PTB, the WHO has earmarked November $7^{\text {th }}$ as World Prematurity Day and creates awareness about the condition and its consequences. In addition, the "Born Too Soon Report "has set a goal to reduce preterm-specific mortality by $50 \%$ by 2025 [8].

The estimated 12.9 million preterm births that occurred in 2005 represent a substantial problem for already overtaxed health, education and social service sectors worldwide ${ }^{[9]}$. Similar to many other indicators in the area of maternal and perinatal health, preterm birth rates reflect the stark health disparities between developed and developing countries like Nigeria ${ }^{[9]}$. The burden of PTB is disproportionately concentrated in Africa and Asia, where about $85 \%$ of all preterm births occur (31\% and 54\%) respectively ${ }^{[10]}$. Furthermore, it should be noted that the high absolute numbers and proportionate share of the overall burden in developing regions of the world are linked to the greater number of deliveries in those regions ${ }^{[9]}$. Preterm births account for $5-25 \%$ of all deliveries and up to $75 \%$ of all perinatal mortality in some series ${ }^{[11]}$. In Nigeria, preterm babies account for $40-60 \%$ of all perinatal deaths ${ }^{[11]}$.

The survival of these preterm infants is a function of both their biological maturity and technological advancement ${ }^{[11,12]}$. The latter has continued to improve in most developed societies, with continuing progress in neonatal intensive care, shifting the limit of viability towards younger gestational ages, with greater than $80 \%$ survival at 28 weeks gestation ${ }^{[13]}$. The same cannot be said of developing countries like Nigeria where inadequate health facilities, inadequate trained health personnel, poverty, illiteracy and lack of political will on the part of the government are still commonplace. A previous study in Benin City, in the Southern part of Nigeria, recorded mortality of $92.6 \%$ in babies of less than 28 weeks' gestation ${ }^{[14]}$.

Hence, the most sensible way of reducing the prevalence of PTBs in resource-challenged societies like ours is through identification and modification of the risk factors associated with PTB. Many factors have been associated with PTB and these include previous preterm birth, pregnancy-induced hypertension (PIH), preterm pre-labour rupture of membranes (PPROM), teenage pregnancy, urinary tract infection (UTI), maternal anaemia, nulliparity, antepartum haemorrhage, age greater than 50 years, education (not beyond secondary school), multiple gestation, maternal medical conditions during pregnancy, previous abortion, smoking and booking status ${ }^{[15-20]}$. Regrettably, the cause of PTB in $50 \%$ of pregnancies is idiopathic $[12,16,18]$

An earlier study in this department reviewed the determinants of neonatal survival following preterm deliveries at UMTH ${ }^{[17]}$. This study was, therefore, undertaken to determine the prevalence, risk factors and neonatal outcomes associated with PTB at the University of Maiduguri Teaching (UMTH) Maiduguri, Nigeria.

\section{MATERIALS AND METHODS}

This was a case-control study of women who had PTBs at the University of Maiduguri Teaching Hospital (UMTH) over a two-year period from $1^{\text {st }}$ January, 2016 to $31^{\text {st }}$ December, 2017. Permission was sought and obtained from the Ethics Committee of the hospital for the conduct of this research. The labour ward register, 
Special Care Baby Unit (SCBU) register and patients' case records were retrieved from the health information unit of the hospital. For each PTB, the next woman that had term delivery was recruited as control.

Information on the sociodemographic characteristics, booking status, previous PTB, twin gestation, HIV infection, Polyhydramnios, Premature Rupture of Membranes (PROM) and birth outcomes were obtained from the case records. The information was coded and transferred onto a profoma designed for the study. This was then transferred into Statistical Package for the Social Sciences (SPSS) software version 23.0 (Armonk New York: IBM Corp.) and analysed, and presented as percentages on frequency tables. Chi square test and student $t$ test were used to analyse for categorical variables and continuous variables respectively. The statistical significance was set at $\mathrm{P}<0.05$.

For the purpose of this study, PTB is delivery before 37 completed weeks; gestational age was calculated from early scan or last menstrual period. Also, for the purpose of this study, antepartum haemorrhage is defined as any bleeding from the female genital tract after 28 weeks of gestation but before the delivery of the baby.

\section{RESULTS}

There were 6,171 deliveries over the 2-year period. Out of which 291 were preterm births, giving a prevalence rate of $4.7 \%$ or 47 per 1000 deliveries. However, 248 cases (with 265 babies) and 248 controls (with 249 babies) with complete information retrieved from the Health information unit were used for further analysis, giving the retrieval rate of $85 \%$.

The mean age of the cases and controls were similar $(26.4 \pm 6.1$ Vs $26.6 \pm 5.3$ years) with $\mathrm{F}=0.15, \mathrm{P}=0.7$, while the mean parity were $3.0 \pm 2.6$ and $3.2 \pm 2.5$ with $(\mathrm{F}=4.6, \mathrm{P}=0.03)$. Nulliparity was commoner among the cases $61(24.6 \%)$ compared to the controls $34(13 . .7 \%)$ with $X^{2}=9.69$,
$\mathrm{P}=0.001$. Similarly, 96(38.7\%) of the cases were unbooked compared to 44(17.7\%) among the conrols $\mathrm{X}^{2}=26.9, \mathrm{P}<0.001$. About $20 \%$ of the cases had no formal education compared to $13 \%$ of the control as shown in Table 1.

Table 2 shows the various risk factors associated with PTB. Preterm birth was independently associated with unbooked status (OR=1.82,CI:1.40-2.36), parity (OR=2.05, CI:1.29-3.26), previous preterm delivery $(\mathrm{OR}=95.2, \quad \mathrm{CI}: 13.10$ 691.99) and pregnancy induced hypertension $\quad(\mathrm{OR}=25.45$, CI:9.13-70.92). Table 2 also shows that antepartum haemorrhage $(\mathrm{OR}=13.89, \mathrm{CI}: 4.92-39.25)$, twin gestation $(\mathrm{OR}=18.18, \mathrm{CI}: 2.40-137.68)$, polyhydramnios $\quad(\mathrm{OR}=2.02, \mathrm{CI}: 1.85-2.22)$ and PPROM $(\mathrm{OR}=5.39, \quad \mathrm{CI}: 2.87-10.15)$ were other risk factors with independent association with PTB. Table 3 shows the birth outcomes of the 248 PTBs. Birth asphyxia occurred in $44(16.6 \%)$ of the cases as opposed to only $3(1.2 \%)$ in the controls and neonatal death was recorded in $43(16.2 \%)$ of the cases as opposed to only $1(0.4 \%)$ recorded in the control arm of the study.

TABLE 1: SOCIO-DEMOGRAPHIC CHARACTERISTICS OF WOMEN WITH PTB

\begin{tabular}{|c|c|c|}
\hline Age & Case $(\%)$ & Control (\%) \\
\hline$<20$ & $13(5.2)$ & $12(4.8)$ \\
\hline $20-29$ & $153(61.7)$ & $140(56.5)$ \\
\hline $30-39$ & $60(24.2)$ & $64(25.8)$ \\
\hline$\geq 40$ & $22(8.9)$ & $24(9.8)$ \\
\hline Total & $248(100.0)$ & $248(100.0)$ \\
\hline \multicolumn{3}{|c|}{ Mean $=26.5 \pm 5.3$} \\
\hline Parity & Case $(\%)$ & Control $(\%)$ \\
\hline Nulliparous & $61(24.6)$ & $34(13.7)$ \\
\hline Parous & $187(75.4)$ & $214(86.3)$ \\
\hline Total & $248(100.0)$ & $248(100.0)$ \\
\hline \multicolumn{3}{|c|}{$\mathrm{X}^{2}=9.49, \mathrm{P}<0.001, \mathrm{OR}=2.05(\mathrm{CI}=1.29-3.26)$} \\
\hline Booking status & Case $(\%)$ & Control (\%) \\
\hline Booked & $152(61.3)$ & $204(82.3)$ \\
\hline Unbooked & $96(38.7)$ & $44(17.7)$ \\
\hline Total & $248(100.0)$ & $248(100.0)$ \\
\hline \multicolumn{3}{|c|}{$\mathrm{X}^{2}=26.9, \mathrm{P}<0.001, \mathrm{OR}=1.82(\mathrm{CI}=1.40-2.36)$} \\
\hline Educational attainments & Case $(\%)$ & Control (\%) \\
\hline Primary & $72(29.0)$ & $78(31.5)$ \\
\hline Secondary & $106(42.7)$ & $111(44.8)$ \\
\hline Tertiary & $20(8.1)$ & $25(10.1)$ \\
\hline None & $50(20.2)$ & $34(13.7)$ \\
\hline Total & $248(100.0)$ & $248(100.0)$ \\
\hline $\mathrm{X}^{2}=26.9, \mathrm{P}<0.001$ & & \\
\hline
\end{tabular}


Obetta Hillary Ikechukwu et.al. Prevalence, risk factors and outcome of preterm births at University of Maiduguri Teaching Hospital (UMTH), Maiduguri, Nigeria: a 2-year case-control study.

TABLE 2: RISK FACTORS ASSOCIATED WITH PTB IN THE 248 WOMEN REVIEWED

\begin{tabular}{|c|c|c|}
\hline Previous Preterm delivery & Case (\%) & Control (\%) \\
\hline Yes & $69(27.8)$ & $1(0.4)$ \\
\hline No & $179(72.2)$ & $247(99.6)$ \\
\hline Total & $248(100.0)$ & $248(100.0)$ \\
\hline \multicolumn{3}{|c|}{$\mathrm{X}^{2}=76.91, \mathrm{P}<0.001, \mathrm{OR}=95.2(\mathrm{Cl}=13.10-691.99)$} \\
\hline $\mathrm{PIH}$ & Case $(\%)$ & Control (\%) \\
\hline Yes & 73(29.4) & $4(1.6)$ \\
\hline No & $175(70.6)$ & $244(98.4)$ \\
\hline Total & $248(100.0)$ & $248(100.0)$ \\
\hline \multicolumn{3}{|c|}{$\mathrm{X}^{2}=73.19, \mathrm{P}=0.03, \mathrm{OR}=25.45(\mathrm{CI}=9.13-70.92)$} \\
\hline Twin gestation & Case $(\%)$ & Control (\%) \\
\hline Yes & $17(6.9)$ & $1(0.4)$ \\
\hline No & $231(93.1)$ & $247(99.6)$ \\
\hline Total & $248(100.0)$ & $248(100.0)$ \\
\hline \multicolumn{3}{|c|}{$\mathrm{X}^{2}=14.76, \mathrm{P}<0.001 \mathrm{~s}, \mathrm{OR}=18.18(\mathrm{CI}=2.40-137.68)$} \\
\hline$\overline{\mathrm{APH}}$ & Case $(\%)$ & Control (\%) \\
\hline Yes & $46(18.5)$ & $4(1.6)$ \\
\hline No & $202(81.5)$ & 244(98.4) \\
\hline Total & $248(100.0)$ & $248(100.0)$ \\
\hline \multicolumn{3}{|c|}{$\mathrm{X}^{2}=39.23, \mathrm{P}<0.001, \mathrm{OR}=13.89(\mathrm{CI}=4.92-39.25)$} \\
\hline HIV infection & Case $(\%)$ & Control (\%) \\
\hline Yes & $6(2.4)$ & $1(0.4)$ \\
\hline No & $242(97.6)$ & $247(99.6)$ \\
\hline Total & $248(100.0)$ & $248(100.0)$ \\
\hline \multicolumn{3}{|c|}{$\mathrm{X}^{2}=3.62, \mathrm{P}=0.06, \mathrm{OR}=6.12(\mathrm{CI}=0.73-51.25)$} \\
\hline Polyhydramnious & Case $(\%)$ & Control (\%) \\
\hline Yes & $6(2.4)$ & $0(0.0)$ \\
\hline No & $242(97.6)$ & $248(100.0)$ \\
\hline Total & $248(100.0)$ & $248(100.0)$ \\
\hline \multicolumn{3}{|c|}{$\mathrm{X}^{2}=6.07, \mathrm{P}=0.015, \mathrm{OR}=2.02(\mathrm{CI}=1.85-2.22)$} \\
\hline PROM & Case $(\%)$ & Control (\%) \\
\hline Yes & $57(23.0)$ & $13(5.2)$ \\
\hline No & 191(77.0) & $235(94.8)$ \\
\hline Total & $248(100.0)$ & $248(100.0)$ \\
\hline
\end{tabular}

TABLE 3: BIRTH OUTCOMES OF THE 265 PRETERM BABIES AND 249 TERM BABIES DELIVERED IN 2016 AND 2017 AT UMTH

\begin{tabular}{|l|l|l|}
\hline & Case (\%) & Control (\%) \\
\hline Normal & $151(57.0)$ & $241(96.8)$ \\
\hline Birth asphyxia & $49(18.5)$ & $6(2.4)$ \\
\hline SCBU admission & $35(13.2)$ & $4(1.6)$ \\
\hline Neonatal death & $43(16.2)$ & $2(0.8)$ \\
\hline
\end{tabular}

Babies that had birth asphyxia were equally admitted into SCBU and some suffered perinatal mortality.

\section{DISCUSSION}

This study has demonstrated that preterm birth remains a significant burden with a hospital-based prevalence rate of 4.7\%. However, this prevalence rate observed in this study is relatively lower than the prevalence rates reported in Enugu, Ilorin, Benin and Kano ${ }^{[14,15]}$. It is also lower than the $15 \%$ national preterm birth rate estimated by WHO for Nigeria in the "Born Too Soon" report ${ }^{[8]}$. This observed prevalence rate in this study is, however, comparable to that reported by Akintayo et al in Ekiti State, Nigeria who reported a preterm birth rate of $5.7 \%{ }^{[18]}$. Prevalence rate as high as $12.7-15 \%$ have been reported in developed societies ${ }^{[18]}$. However, this is mainly related to medically indicated preterm birth. The plausible explanation for this relatively low prevalence rate of PTB in this study may not be unconnected with the fact that majority of the deliveries usually occur outside the hospital setting as many of the pregnant women do not attend antenatal care. A study has also shown that over $50 \%$ of births are delivered outside the hospital setting in Nigeria ${ }^{[20]}$.

So many risk factors have been associated with PTB and these include teenage pregnancy, unbooked status, educational attainments, previous preterm delivery, twin gestation, pregnancy induced hypertension, antepartum heamorrhage, maternal HIV infection, polyhydramnios and premature rupture of membranes ${ }^{[19]}$.

This study has demonstrated no significant association between maternal age and the risk of PTB and this finding is at variance with previous studies that showed a significant association between teenage pregnancy and preterm birth ${ }^{[2,15]}$. OmoleOhousi and Attah working in Kano showed a significant association between PTB and teenage pregnancy ${ }^{[15]}$.

This study has again added to the body of evidence that unbooked status has a significant association with PTB and this finding is in consonance with previous documentations in literature ${ }^{[19]}$. A study has shown that being "unbooked" and receiving no antenatal care is the only modifiable maternal characteristic that increased the risk of PTB ${ }^{[20]}$. Azeez et al reported that unbooked mothers are five times more likely to have preterm delivery ${ }^{[20]}$. The likely explanation for the high prevalence rate of preterm birth among "unbooked" pregnant women is that a potential problem 
which may result in preterm birth is likely to be detected early if the pregnancy is booked and adequately supervised. Such a pregnant woman may have her pregnancy managed till term if booked early and properly supervised. Early booking and antenatal care also allow both the caregiver and the family some time to prepare for the PTB. The family can make adequate preparations to care for the special needs of the preterm baby and also the physician would have counselled, and sometimes, even referred the mother to a tertiary centre for better care. This further buttresses the need for booking as one of the ways of reducing PTB.

Previous preterm delivery has shown significant association with preterm birth in this study and this finding had been demonstrated in previous studies ${ }^{[18]}$. This association may be due to the persistence of unidentified problems in some women triggering preterm delivery. This risk factor may be modified with preconception care and also early booking which allows the physician ample time to diagnose the underlying cause of PTB and proffer solutions. This is true for cases like cervical incompetence and uterine abnormalities that can be surgically corrected.

The association between pregnancy induced hypertension and PTB was also significant in this study. In this study, $29.4 \%$ of the cases reviewed had pregnancy induced hypertension. It is possible that reduced placental perfusion, coupled with concerns about maternal or fetal safety will necessitate PTB. Pregnancy-induced hypertension is an important cause of PTB globally. A study looking at the biological determinant of late PTB found that placental ischaemia as a result of hypertensive diseases in pregnancy increased the odds of late PTBs. [20] Hypertension during pregnancy negatively impacts placental blood flow and leads to poor fetal growth and obstetric emergencies, which increase the odds of having a preterm surgical delivery or induced preterm delivery as a lifesaving measure for the mother and fetus.
This study has also revealed a significant association between antepartum haemorrhage and PTB and this finding is consistent with previous studies ${ }^{[11,14]}$. It has been suggested that antepartum haemorrhage may lead to preterm birth due to irritation of the myometrium by blood and this has been thought to provoke uterine activity leading to PTB ${ }^{[2]}$.

Twin gestation and polyhydramnios were significantly associated with PTB and this finding is in agreement with previous studies ${ }^{[1-3]}$. The overstretching of the myometrium and possibly the membranes leads to increased contractile activity and premature shortening and opening of the cervix. Twin gestation is also more likely to be complicated by pregnancy induced hypertension, antepartum haemorrhage and diabetes mellitus and all of these may serve as a driver of preterm delivery.

Premature rupture of membranes was strongly associated with preterm birth in this study and this finding agreed with previous studies ${ }^{[15,17]}$. It has also been associated with sub-clinical chorioamnionitis and Chlamydia vaginitis, both of which have been associated with preterm delivery ${ }^{[11]}$. Its role is, therefore, inconclusive because it is not clear whether premature rupture of membranes is the primary event that leads to PTB or whether there is an underlying problem like subclinical chorioamnionitis that leads to both premature rupture of membranes and preterm delivery. Sub-clinical chorioamnionitis can initiate labour by stimulating the production of interleukin-1 [11]. Interleukin-1 is known to indirectly serve as a signal for the initiation of labour in cases of intrauterine or systemic infection by inducing prostaglandin production by intrauterine tissues. ${ }^{[11]}$

This study has shown no significant association between maternal HIV infection and PTB and this contrasts with previous documentations in literature ${ }^{[1,11,20]}$. The effect of maternal HIV infection has been shown to be worse in HIV infected pregnant women who do not attend antenatal care and 
do not have access to highly active antiretroviral therapy (HAART) ${ }^{[20]}$. On the other hand, expectant mothers with HIV who booked and are on HAART are categorized as high risk in the antenatal care clinic and this knowledge is embodied by both the expectant mothers who are striving to deliver a healthy free-HIV baby and the healthcare team who are striving to prevent transmission from mother to child. A study has shown that receiving care for prevention of mother to child transmission (PMTCT) of HIV significantly reduced the risk of early and moderate preterm delivery but not late preterm delivery ${ }^{[20]}$.

Perinatal asphyxia, admission into special care baby unit (SCBU) and neonatal deaths were significantly associated with preterm birth in this study and these findings only reaffirrmed previous studies $[11,18]$. Given that $43(16.2 \%)$ resulted in perinatal deaths, efforts to identify those at high risks of preterm birth are an important step towards reducing perinatal mortality. Improving the neonatal services with faciltites to cater for the needs of the preterm babies such as surfactant will go a long way in reducing the perinatal mortalities associated with PTB.

\section{CONCLUSION}

The prevalence rate of PTB at the UMTH is $4.7 \%$ and is associated the previous PTB, unbooked status, twin gestation, polyhydramnios, APH and PIH. Efforts should be intensified on educating women of reproductive age group on the benefits of antenatal booking in pregnancy and quality antenatal care as this would provide ample opportunity for early detection and proper management of women at risk.

Data availability: All the necessary data are included in the manuscript

Conflict of Interest: The authors declare that they have no conflict of interests.
Funding: There is no external source of fund outside the authors

\section{ACKNOWLEDGMENTS}

Authors are grateful to the health information unit staff, the special baby care unit (SBCU) staff, and the nurses in the labour ward who facilitated data collection for the conduct of this research.

Ethical approval: Ethical approval for this study was gotten from the ethics committee of University of Maiduguri Teaching Hospital.

\section{REFERENCES}

1. Blencowe $\mathrm{H}$, Cousens $\mathrm{S}$, Chou $\mathrm{D}$, Oestergaard M, Say L, Moller AB, Kime M, Lawan J. Born Too Soon Preterm Birth Action Group (2013) Born Too Soon: The Global Epidemiology of 15 Million Preterm Births. Reprod Health, 10 suppl. S2. ISSN 1742-4755.

2. Jones G. Late Miscarriage and Early Birth. In: Philip NB, Louise CK (eds). Obstetrics by Ten Teachers, $19^{\text {th }}$ edition, Book Power with Hodder Arnold, 2011: 132-143.

3. Amy B, Becker C. Pregnancy Complications. In: Collins S, Sabaratanam A, Kevin H, Simon J, Lawrence I (eds). Oxford Handbook of Obstetrics and Gynaecology, $3^{\text {rd }}$ edition. Oxford University Press; 2013: 49-106.

4. Taylor M, Rundle S. Preterm Labour. In: Leusley DM, Kilby MD (eds) Obstetrics and Gynaecology, An Evidence-based Text for the MRCOG, $3^{\text {rd }}$ edition, CRC Press Taylor and Francis Group Boca Raton London, New York; 2016: 327-337.

5. Steer P. The epidemiology of Preterm Labour. BJOG 2005, 112 (suppl. 1): 1-3.

6. Quigley MA, Poulsen G, Boyle E, Wolke D, Field D AlfiRevic Z, Kurinczuk JI: Early term and late preterm births are associated with poorer school performance at age 5 years: a cohort study. Arch Dis Child Fetal Neonatal Ed 2012; 97 (3): 167-173.

7. Woythaler MA, McCormick MC, Smith VC. Late preterm infants have worse 24month neurodevelopmental outcomes than term infants. Peadiatrics 2011, 127: e622629. 
8. Delivery Action on Preterm Births. Lancet. 2013; 385 (9905): 1610. No authors listed.

9. Stacy B, Daniel W, Lale S, Ana PB, Mairo M, Jennifer HR, Craig R, Ramkumar M, Paul FA. The Worldwide Incidence of Preterm Birth: A Systematic Review of Maternal Mortality and Morbidity. Bulletin of the World Health Organization 2010; 88:31-38.

10. Chukwuemeka AI, Osaheni LL, Euzebus CE, Gideon I, Peter ON, Sunday GM, Isaac NA. Prevalence and Perinatal Mortality Associated with Preterm Births in a Tertairy Medical Center in Southeast Nigeria. Int. J Women's Health. 2014; 6:881-888.

11. Olugbenga AM, Suleiman BM, Adesiyun OO, Adeniyi A. Prevalence and Determinants of Preterm Deliveries in the University of Ilorin Teaching Hospital, Ilorin Nigeria. Paediatr Rep. 2010 Jun 18; 2 (1): e3.

12. Ashley SR. Late Pregnancy Complications. In: Alan HD, Lauren N, Neri L, Ashley SR (eds). Current Diagnosis \& Treatment Obstetrics \&Gynaecology, $11^{\text {th }}$ edition; McGraw Hill 2013: 250-266.

13. Madhra M. Prematurity. In: Magowan BA, Owen P, Thomson A (eds). Clinical Obstetrics and Gynaecology, $3^{\text {rd }}$ edition, Saunders Elsevier; 2014: 301-304

14. Ibhanesebhor SE, Afadapa MA. Epidemiology of Preterm Deliveries in Benin City. Nig J Paediatr. 1996; 23:27-32.

15. Omole-Ohousi A, Attah RA. Risk factors of preterm deliveries at Aminu Kano Teaching
Hospital, Kano; Nigeria. SAJMS 2012; 1:310

16. Dutta DC. Preterm Labour. In: Konar H (ed). Textbook of Obstetrics, $7^{\text {th }}$ edition. New Central Book Agency (P) Ltd, London; 2013: 314-326.

17. Bako B, Idrisa A, Garba MA, Pius S, Obetta HI. Determinants of Neonatal Survival Following Preterm Deliveries at University of Maiduguri Teaching Hospital, Maiduguri, Nigeria. Tropical Journal of Obstet Gynaecol;Vol:34, 2017 :39-44.

18. Akintayo A.A, Awoleke J.O, Ogundare E.O Olatunya O.S, Aduloju O.P. Preterm births in a resource-constrained setting: sociobiologic risk factors and perinatal outcomes. ResearchGate; 2015:Vol 49, Number 4

19. Hamilton BE, Mini no AM, Martin JA, Kochanek KD, Strobino DM, Guyer B. Annual summary of vital statistics:2005, Paediatrics 2007;119: 345-360

20. Azeez B, Chinyere E, Osayame E, Nancy W, Jenna L, Iretiola F, et al. Characteristics and Risk Factors of Preterm Births in a Tertiary Centre in Lagos, Nigeria. The Pan African Medical Journal. 2016; 24:1

How to cite this article: Obetta HI, Babagana B, Nweze SO et.al. Prevalence, risk factors and outcome of preterm births at University of Maiduguri Teaching Hospital (UMTH), Maiduguri, Nigeria: a 2-year case-control study. International Journal of Research and Review. 2021; 8(6): 67-73. DOI: https://doi.org/10. 52403/ijrr.20210610 